\title{
Praxis editorial
}

António Faria-Vaz*

The coin is two sided; it is not only the scientist who should adhere to high ethical principles but also the reviewer, the publication committee, and the section editors who should serve with good faith, thus contributing much more to the enhancement of science. ${ }^{1}$

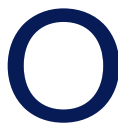
processo editorial de uma revista científica é um processo complexo sujeito a inúmeros problemas éticos.

A Ética pode definir-se como a parte da filosofia que se ocupa dos costumes, da moral, dos deveres do homem ou, segundo outros autores, que trata da correcção ou incorrecção das acções humanas.

No âmbito editorial, são classicamente considerados,como tal, a fabricação e a falsificação de dados, o plagiarismo, a publicação redundante, os conflitos de interesse, as questões de autoria, a protecção e a segurança dos participantes em investigação e, finalmente a responsabilidade do revisor dos manuscritos propostos pelos autores para publicação na revista. ${ }^{2}$

A importância de cada um destes problemas e as suas consequências éticas e legais, têm sido objecto de intenso debate cujos resultados se encontram traduzidos em extensa literatura e mesmo em linhas de orientação editorial. ${ }^{3,4}$

Na Revista Portuguesa de Clínica Geral, também têm sido a gestão editorial e o processo de decisão editorial as questões que, no plano ético, nos têm colocado os maiores desafios.

No que respeita à gestão editorial, temos procurado criar e optimizar ferramentas de apoio que nos permitam, de uma forma continuada e permanente, identificar os diversos passos do processo editorial. Para tanto, dispomos, neste momento, de duas aplicações informáticas que nos permitem a partilha da informação sobre o processo editorial («forum da revista»),o acesso aos manuscritos em gestão e, ainda a recolha de um

*Director da Revista Portuguesa de Clínica Geral importante acervo de informação sobre a nossa publicação.

O processo de gestão editorial dos manuscritos submetidos à RPCG assenta em quatro pilares fundamentais, que são a análise crítica dos editores e do conselho editorial, a revisão por pares, a resposta dos autores às sugestões de alteração propostas pela revista e, finalmente, (n) a revisão técnica dos artigos antes da sua publicação.

A análise crítica dos editores e do conselho editorial, recentemente instituída, avalia em primeira instância o manuscrito logo após a sua recepção pelo editor, em quatro grandes dimensões (pertinência; novidade; cumprimento das normas e particularidade que justifica a sua publicação). Esta análise procura atingir quatro objectivos essenciais, nomeadamente o de garantir consistência e a harmonização do processo de revisão editorial, agilizar o processo editorial e, simultaneamente, permitir e facilitar a aquisição de competências de gestão editorial pelos editores.

A revisão por pares, definida como um processo de avaliação da pertinência, interesse e originalidade de um manuscrito por peritos qualificados, é um dos elementos essenciais do processo de revisão científica, considerada hoje como uma das pedras basilares do processo editorial de uma revista científica.

Neste tipo de revista, os pares têm um papel fundamental na garantia da qualidade do que é publicado, pois a eles se deve a identificação de fragilidades, o escrutínio da inovação, a sugestão de modificações, o aconselhamento, procurando garantir um nível de excelência nos artigos publicados pela revista.

Esta é, segundo alguns autores, a maior dificuldade que um revisor enfrenta ${ }^{5}$ mas é, seguramente,um recurso significativo para promover a qualidade dos artigos. Tarefa exigente, que requer disponibilidade, saber, sensibilidade e elevados padrões morais e éticos. Diríamos que, nesta configuração, o revisor é um valor acrescentado para um autor, pois é o seu contributo que possibilita, por exemplo, a publicação de um artigo, que, embora com mérito científico e originalidade, 
apresente necessidades de reformulação que só uma mão reflectida lhe poderá proporcionar. Por isso, não é ousado afirmar que uma revista depende, nesta perspectiva, da qualidade dos seus revisores (e da respectiva disponibilidade).

Contudo, é ao conselho editorial que cabe a última palavra no que concerne à decisão de publicar um manuscrito, atento à apreciação dos revisores (dois, no caso de concordância ou 3 em caso de discordância) e do editor responsável pelo artigo. Incluindo-se aqui critérios de oportunidade, a decisão final estabelecerá também a ordem pela qual os artigos serão publicados.

Como afirmam Flanagin e Glass o prestígio e a influência de uma revista biomédica estão intimamente associados ao sistema de controlo de qualidade e ao método de selecção de artigos que antecede a publicação. Nesta circunstância, acrescentam estes autores, as actividades essenciais são a selecção e a melhoria dos artigos submetidos para publicação. Estas tarefas são geralmente realizadas pelo conselho editorial e pelos revisores. Dizem-nos por fim, que esta metodologia assenta a sua essência em juízos humanos e, por isso mesmo, está sujeita a erros e a viezes. ${ }^{6}$

Outra dimensão do processo editorial está directamente relacionada com a sua finalidade principal, que é a disseminação da informação científica. Neste domínio e ainda que assumindo o conflito, sempre latente, entre a vontade de uma rápida publicação dos autores e as exigências dos editores e revisores que pro- curam garantir a qualidade e o rigor dos artigos a publicar, teremos de contar sempre com dois factores essenciais: a disponibilidade dos editores, dos revisores e dos autores para promoverem a revisão e reformulação dos artigos e a sua competência técnica e científica para a concretizar.

Este é o procedimento habitual na nossa revista, que muito depende da vontade e da bondade de uma equipa que foi aprendendo com os seus próprios erros, as suas dúvidas e incertezas. Não atingimos a perfeição, nem somos impolutos. Somos humanos procurando apenas fazer o melhor na dignificação da nossa especialidade e da nossa revista.

Boa leitura!...

\section{REFERÊNCIAS BIBLIOGRÁFICAS}

1. Epstein Y. Scientific ethics. J Appl Physiol 92: 2226, 2002.

2. Benos DJ, Fabres J, Farmer J, et al. Ethics and scientific publication. Adv Physiol Educ 2005; 29:59-74

3. Committee on Publication Ethics (COPE). Guidelines on good publication practice. J Postgrad Med 2000; 46:217-221

4. Scott-Lichter D. aEPC, Council of Science Editors. CSE's White Paper on Promoting Integrity in Scientific Journal Publications (online). http://www.nature.com/nature/peerreview/debate/nature04994.html [acesso em 26.06.2010].

5. Provenzale J. M, Stanley R. J. A systematic guide to reviewing a manuscript. J. Nucl. Med. Technol., , 2006; 34 (2): 92-99.

6. Glass RM, Flanagin A. Scientific Publishing in Encyclopedia of Bioethics. Editor Stephen G. Post . Encyclopedia of bioethics 3rd edition. Vol 4. New York. Macmillan Reference USA. 2004. p.2401-2409. 